\title{
Práticas pedagógicas e desafios do ensino da História Afro-brasileira no curso de informática para Jovens e Adultos
}

\author{
Manoela Bernardi Ferreira* \\ Flávia Ferreira** \\ Eduardo Muniz Bocchi ${ }^{* *}$
}

\begin{abstract}
Resumo
O presente artigo é decorrente de reflexões sobre a prática docente em História realizada no Estágio Supervisionado, em uma turma do Curso de Informática e Comunicação da Escola de Turismo e Hotelaria Canto da Ilha, ofertado para Jovens e Adultos. O trabalho desenvolvido, que gerou muitas opiniões e pontos de vista controversos, abordou algumas problematizações acerca da História afrobrasileira, correlacionando-a ao aprendizado obtido nas aulas de informática. Muitos foram os desafios e dificuldades encontrados por nós, estagiários, no decorrer desta etapa de formação. Assim, neste texto, procuramos expor tais desafios e também nos apropriamos dos trabalhos finais dos alunos, os trabalhos de Conclusão do Curso, com a finalidade de questionar o papel de atores e atrizes afro-brasileiros na mídia. Palavras-chave: estágio supervisionado em história, educação de jovens e adultos, história afro-
\end{abstract} brasileira.

Pedagogical PRACTICES and teaching challenges of the afro-brazilian history in the youth and adults computer course

\section{Abstract}

This article is the result of reflections about the practice of History teaching in the Supervised Internship of a class from Computer and Communication Course of Canto da Ilha Tourism and Hospitality School (Escola de Turismo e Hotelaria Canto da Ilha), offered for Youth and Adults. This activity, which generated many controversial opinions and points of view, addressed some problematizations about AfroBrazilian history correlated to the obtained learning in computer classes. We, trainees, encounter many challenges and difficulties during this formation stage. Thus, in this text, we try to expose such challenges. We also appropriate the students' final works, the End of Course Works, aiming to question the role of Afro-Brazilian actors and actresses in the media.

Keywords: supervised internship in history teaching, youth and adult education, afrobrazilian history.

\section{Introdução}

Este artigo apresenta reflexões desenvolvidas durante o estágio supervisionado em História e aborda a respeito da elaboração de uma oficina sobre a História dos afrobrasileiros, contextualizando-a, na mídia, para uma turma da Educação de Jovens e Adultos. São compartilhados os desafios e possibilidades que foram vivenciados no decorrer da oficina ministrada e também como foi a elaboração e o preparo do plano de

\footnotetext{
*_Graduada em História pela Universidade Federal de Santa Catarina. E-mail: manuvf@ hotmail.com.

* Graduada em História pela Universidade Federal de Santa Catarina. E-mail: flaviaferreira08@hotmail.com.

***araduado em História pela Universidade Federal de Santa Catarina. E-mail: edumuniz1@gmail.com.
} 
aula, bem como os desafios e imprevistos que se apresentaram no momento da realização da oficina, com um tema ainda cheio de preconceitos, e as surpresas que surgiram ao final do semestre.

O estágio, realizado no ano de 2015, perdurou todo o ano letivo, sendo efetivado na Escola de Turismo e Hotelaria Canto da Ilha, localizada no bairro Cachoeira do Bom Jesus, Florianópolis (SC), em uma turma do curso de Informática e Comunicação, ofertado como Formação Inicial e Continuada (FIC). Primeiramente é interessante relatar a surpresa que o grupo de estagiários teve ao se deparar com a exigência de realizar o estágio obrigatório da graduação de História em uma sala de Informática, ainda mais com alunos de variadas faixas etárias. Os alunos advinham de praticamente todos os estados do país, além de possuírem idades que iam dos 19 aos 62 anos. Na ocasião, muitas dúvidas e medos afloraram, além do descontentamento inicial dos estagiários. O que faríamos, como estudantes de História, junto a uma turma mista e cheia de peculiaridades como aquela do Curso de Informática e Comunicação?

A resposta veio com base nas leituras de Paulo Freire. ${ }^{1}$ Em um primeiro momento, o estágio se tornou uma aflição para nós estagiários, mas quando nosso olhar focalizou a formação integral dos alunos, e não mais, tão somente, as aulas e conteúdos, tudo começou a tomar um rumo e a fazer sentido para o grupo. A meta agora seria elaborar oficinas que valorizassem a informática, tratando-a na forma de diálogos, com temáticas e metodologias próprias ao ensino de História.

Paulo Freire (1996), que representa um marco para a EJA, afirmava a necessidade de o educador (re)educar-se para atuar ao lado dos oprimidos e a favor deles. Seu método de alfabetização de adultos discorre acerca de uma educação em que o objetivo maior é conscientizar o aluno. Isso significa, em relação às parcelas desfavorecidas da sociedade, levá-las a entender sua situação de oprimidas e agir em favor da própria libertação.

No início do segundo semestre, na Escola de Turismo e Hotelaria Canto da Ilhanos foi apresentada, em uma reunião, a programação do ensino das matérias nos cursos de: Gastronomia e Identidade Cultural, Informática e Comunicação, Língua Espanhola, Língua Inglesa, Organização de Eventos, Técnico em Hospedagem e

Durante as aulas de Estagio 2, realizadas durante as primeiras semanas do segundo semestre, foi realizado na UFSC, um Seminário em sala de aula abordando e debatendo o livro de Paulo Freire, "Pedagogia da autonomia: Saberes necessários à prática pedagógica". 
Auxiliar de Pessoal. Ao dar início às aulas, a coordenação da Escola nos passou um programa de ensino com todas as matérias que seriam abordadas no decorrer do semestre. De acordo com o cronograma da turma, ficaria a cargo da primeira oficina tratar sobre o tema "Mídia e democratização da informação", tratando sobre a história da tecnologia, e, na segunda oficina, a tarefa de abordar sobre a "Revolução Industrial". Porém, devido à data agendada para nossa segunda aula ser perto da semana da Consciência Negra, e também pelo fato de que o tema dado aos alunos da Informática para realizarem os seus Trabalhos de Conclusão de Curso (TCC) ${ }^{2}$ ser referente também a esse assunto, nos foi dito para mudar o tema da oficina planejada. Todavia, o tema para esta segunda oficina foi solicitado somente três semanas antes da data da aula prevista, sendo que esta já havia sido marcada previamente no começo do semestre, em nossa primeira reunião com a coordenação.

A proposta de organizar a oficina retratando e contextualizando a presença de afro-brasileiros nos meios de comunicação social, e em como essa cultura midiática os representa, definiu-se, na verdade, como um desafio para nós. Afinal, o grupo havia se preparado para trabalhar com um assunto totalmente diferente, que, conforme a proposta do Curso, seria "Ideologia, consumismo e meio ambiente". Dentro dessa temática havíamos optado, então, por realizar uma oficina sobre Revolução Industrial, tema escolhido pelo grupo de estágio juntamente com a professora da turma e a coordenação escolar.

Naquele momento, entretanto, soubemos o que de fato é ser um professor. Desafios surgem e o docente deve possuir a capacidade de se adequar às demandas do contexto escolar, já que estes fazem parte da docência. Encaramos a mudança como uma possibilidade de testar nossa capacidade de lidar com um reajuste curricular. No fundo sabíamos que seria uma aula de grande potencial educativo para todos nós.

Segundo a proposta curricular para o $\mathrm{EJA}^{3}$ o ensino de História é fundamental, pois permite aos alunos uma reflexão tanto social quanto política e cultural acerca do contexto no qual alunos estão inseridos, auxiliando na compreensão de espaços e

No final do curso de Informática e Comunicação são requisitados aos alunos a elaboração de um trabalho final.

Material da Proposta Curricular do $2^{\circ}$ Segmento. Elaborada pela Coordenação Geral de Educação de Jovens e Adultos COEJA, a Proposta Curricular para o $2^{\circ}$ segmento da Educação de Jovens e Adultos. Volume 2. História. Disponível em: http:/portal.mec.gov.br/secad/arquivos/pdf/eja/propostacurricular/segundosegmento/vol2_historia.pdf. Acesso em: 14 abr. 2016. 
identidades. Dentro da sala de aula, temática e metodologias do ensino de História possibilitam uma troca mútua de conhecimento entre o professor e alunos, possibilitando que estes produzam suas próprias interpretações, além de tirar dúvidas e abrir novos caminhos para seu próprio processo educativo.

\section{Pesquisando sobre o tema e (re)planejando}

O tema sobre afrodescendentes é muito rico em possibilidades. Tanto é que a Lei $\mathrm{n}^{\text {o }} 10.639$ de 2003, estabelece obrigatoriamente o ensino de história e cultura afrobrasileira para o ensino fundamental e médio. Essa lei altera a Lei de Diretrizes e Bases da Educação Nacional e tem por objetivo promover uma educação que reconheça e valorize a diversidade, comprometendo-se com as diversidades do povo brasileiro. A Lei 10.639/03, essencial na história das lutas anti-raciais em prol da democratização do ensino, foi alterada pela Lei 11.645/08, tornando-se obrigatório o ensino de História e cultura afro-brasileira e indígena em todos os níveis de ensino em todas as escolas, públicas e particulares. Tal ensino de História visa "garantir uma ressignificação e valorização cultural das raízes africanas que formaram a diversidade cultural brasileira. Portanto, os professores exercem importante papel no processo de luta contra o preconceito e a discriminação racial no Brasil." ${ }^{4}$

O grupo de estágio encarou o desafio de elaboração dessa nova oficina e em torno de três semanas o projeto foi modificado para que a questão dos afrodescendentes na mídia e sociedade fosse integrada à temática do projeto de estágio. Tal incorporação não foi somente em decorrência da semana da consciência negra, que estava incluída no conteúdo curricular para ser trabalhado, mas para embasar, dar sustentação e suporte à elaboração do Trabalho de Conclusão de Curso dos alunos que, igualmente, estava muito próximo da entrega, faltando somente duas semanas de aula para o prazo final.

A sugestão dada pela professora responsável pela turma de informática foi de que a aula pudesse elucidar sobre como a mídia trabalha e se apropria do assunto, por meio dos papéis que os atores negros e atrizes negras, socialmente, representam. Muitos sujeitos negros, populares ou não, sofreram e/ou sofrem algum tipo de preconceito/racismo. Há muitos depoimentos de jogadores de futebol, atrizes, cantores, médi-

4 Disponível em: <http://educador.brasilescola.uol.com.br/estrategias-ensino/lei-10639-03-ensino-historia-cultura-afrobrasileira-africana.htm.> Acesso em: 23 abr. 2016. 
cos, entre outros, sobre essa questão. Mas, para se chegar até esse assunto, o grupo de estágio considerou que seria preciso discutir com os alunos alguns aspectos da história dos afro-brasileiros, como, por exemplo, a escolha do tema sugerido. Isso não só foi um desafio para o estágio, mas para a própria elaboração do currículo, que visava unir a informática com o ensino de História, o que exigiu a inserção de novas pautas de discussão ao longo das aulas, como será observado mais adiante.

A EJA é uma etapa da educação básica destinada aos jovens e adultos que não tiveram acesso ou não concluíram os estudos no tempo regular de ensino previsto para a conclusão do ensino fundamental e do ensino médio. O papel da EJA não se limita apenas à escolarização, mas também reconhece a educação como direito humano fundamental para a constituição de jovens e adultos autônomos, críticos e ativos frente à realidade em que vivem, respeitando as diferenças culturais.

Devido a essa diversidade de educandos, encontramos várias formas de pensamentos entre os educandos, opiniões que se formam devido às diferentes experiências de vida de cada um. No pensamento do autor Paulo Freire, o ensinar exige respeito aos saberes dos educandos. É preciso respeitar os saberes que os educandos carregam e levam consigo para a sala de aula. A prioridade deve ser discutir com eles a realidade na qual estão inseridos e aproveitar os seus conhecimentos sobre a sua comunidade, na prerrogativa de criar uma "intimidade" entre os saberes curriculares e a experiência social de cada sujeito (FREIRE, 2008). Valorizando a sabedoria dos alunos e estabelecendo analogias e ligações com a realidade deles, gera-se um diálogo no processo de aprendizagem, ao mesmo tempo em que os estudantes "vão se sentir menos tímidos, rompendo assim o desconforto de estar aprendendo tardiamente". 5

Paulo Freire (2008), que representa um marco para a EJA, afirmava a necessidade de o educador (re)educar-se para atuar ao lado dos oprimidos e a seu favor. ${ }^{6}$ Em sua concepção, o professor deve perceber o que os alunos esperam com os estudos, e com base nessa informação, estabelecer uma prática que acolha as diversas necessidades de aprendizagem. Sendo assim, os professores podem e devem capitalizar isso por meio de atividades que remetam ao cotidiano deles, trabalhando o legado da

\footnotetext{
5 Disponível em: <http://www.planetaeducacao.com.br/portal/impressao.asp?artigo=877>. Acesso em: 15 dez. 2016.

6 Disponível em: <http://www.planetaeducacao.com.br/portal/impressao.asp?artigo=877>. Acesso em: 15 dez. 2016.
} 
educação popular com projetos que unam informações teóricas com experiências de vida.

Entendemos que educar é muito mais do que reunir pessoas dentro de uma sala de aula e transmitir-lhes um conteúdo pronto. A proposta de Paulo Freire, a qual permeia e subsidia o nosso processo de elaboração e implementação de oficinas, baseiase na realidade do educando, levando-se em conta suas experiências, suas opiniões e sua história de vida. Por isso, diálogos abertos e perguntas provocativas foram os meios utilizados para conhecer e saber um pouco mais de cada aluno, sua vida, origens, gosto e ambições individuais.

A Escola de Hotelaria e Turismo Canto da Ilha é voltada para jovens e adultos trabalhadores, contudo, apresenta uma organização curricular e uma concepção de ensino diferentes da EJA de Florianópolis. Um dos objetivos dessa Escola é preparar jovens e adultos para o mercado de trabalho, a partir dos cursos de formação humana e profissional.

Para a prática obrigatória do estágio supervisionado, realizado de acordo com as normas da UFSC, atuamos junto ao curso de Informática e Comunicação. Um dos objetivos de tal curso, que também perpassa as demais classes oferecidas pela Escola de Turismo e Hotelaria Canto da Ilha ${ }^{7}$, é inserir os discentes dentro de uma sociedade que exige qualificação na área da computação, no intuito de abrir novos caminhos profissionais, esteja o aluno precisando ou não do computador para o trabalho. A tecnologia visa melhorar e auxiliar o trabalho e é, por esse motivo, que a maioria dos alunos procura a aula de informática. Para cada estudante foi importante o contato com o microcomputador, pois, além de qualificar sua mão de obra, ele possibilita a inserção social ao mundo digital.

Quando iniciamos nosso estágio, perguntamos à turma o motivo pelo qual estavam fazendo aquele Curso. Apesar de a maioria responder que objetivava se atualizar para melhor se inserir no mercado de trabalho, uma parte deles queria somente descobrir e se relacionar melhor com o mundo digital. Alguns queriam aprender a mexer nas redes sociais para falar com suas famílias, outros aprender a fazer pesquisas de assuntos variados na internet, saber fazer seus próprios currículos vitae e outros,

\footnotetext{
A Escola possui diversos cursos oferecidos a comunidade. Dentre eles, o curso de Informática e Comunicação, Gastronomia e Identidade Cultural, Línguas Espanhola e Inglesa, Organização de Eventos, Técnico em Hospedagem e Auxiliar de Pessoal.
} 
ainda, aprender a encaminhar um e-mail. O educando, por ser cidadão trabalhador, quer sentir-se sujeito ativo e participativo das atividades em sala. Ele quer ter a possibilidade de crescer na cultura, no social e no âmbito econômico ${ }^{8}$.

A um professor da EJA é exigido uma maior interação, compreensão e receptividade às expectativas dos alunos. Por isso, a abertura, flexibilidade e um bom inter-relacionamento precisam também ser artifícios presentes em sala de aula. A disponibilidade se faz necessária, pois muitas vezes nos deparamos mediando conflitos e contribuindo na recuperação da autoestima desses educandos.

Nesse contexto, seja qual for o tipo de classe social, é grande a responsabilidade do professor de História, pois ele se torna aquele capaz de defender e de inserir discussões que possibilitem a reflexão sobre a luta de classes e sobre o legado da educação popular nos processos formais de escolarização e educação de jovens e adultos trabalhadores. Em outras palavras, o perfil do professor da EJA é muito importante para o sucesso do aluno que vê o professor como um modelo a seguir. Ele tem o compromisso de mostrar que a EJA é uma educação possível e que é capaz de mudar significativamente a vida desses sujeitos, permitindo a estes reescreverem suas histórias e, também, compreenderem melhor as realidades diárias. Ele é responsável por incentivá-los a acreditar nas possibilidades, a buscar suas metas e a acreditar no seu crescimento pessoal e profissional.

Logo, o professor de História deve ser alguém que domine não apenas os métodos de construção de conhecimento histórico, mas também um conjunto de saberes e mecanismos processuais que possibilitam a socialização desse conhecimento histórico. Para Tardif; Lessard e Lahaye (1991, p. 224) "saber alguma coisa não é mais suficiente para o ensino, é preciso também saber ensinar"”.

Tendo em vista o legado freiriano, do qual procuramos nos aproximar por acreditar nessa valiosa visão de educar, o projeto de ensino efetivado/desenvolvido por meio da oficina sobre "o negro na Mídia", trabalhado com a turma de técnico em Informática, no segundo semestre de 2015, teve como princípio explanar mais acerca da

\footnotetext{
8 Disponível em: <http://www.planetaeducacao.com.br/portal/impressao.asp?artigo=2069>. Acesso em 12 nov. 2016.

9 Disponível em:<http://www.planetaeducacao.com.br/portal/impressao.asp?artigo=877>. Acesso em: 15 nov. 2016.
} 
história dos afrodescendentes e como sua historicidade é parte pertinente do debate que enfrentamos em nossa sociedade globalizada, referindo-se à questão do racismo.

Nicodemos (2013) ratifica a importância de explorar o legado da educação popular, em radicalizá-lo como estratégia de escolarização pelas políticas públicas, como colocado também por Miguel Arroyo (2001). É por essa necessidade que olhar para o educando é extremamente necessário para tal modalidade, para o reconhecimento do sujeito dentro de sua classe econômica e social. A EJA, então, é visualizada como o espaço educacional que conseguiu incorporar esse tipo de educação, muito embora não esteja isenta de uma série de limites sobre os quais não temos espaço para tratar aqui.

Paulo Freire (1996) indica que, muito além de transmitir conhecimento, o professor deve ser um intermediário. Seu principal papel é ensinar o aluno a "pensar" e a questionar por si mesmo, e não mais receber passivamente as informações como se fosse um depósito do educador. A maior responsabilidade do docente é a de agir como sujeito em meio ao mundo e de ensinar para os seus educandos o conhecimento acumulado historicamente, dando-lhes a oportunidade de também atuarem como protagonistas na sociedade.

No primeiro encontro dos grupos de estágio junto com a coordenação da Escola, seria decidido o tema das oficinas/aulas. Foi solicitado, pela coordenação, que a segunda oficina que o grupo trabalharia seria a respeito da questão do trabalhador. $\mathrm{O}$ tema precisaria, a pedido da escola, seguir uma linha de raciocínio a partir da exibição do filme "Tempos Modernos", de 1936. O filme, inclusive, também foi requisitado pela coordenação para ser exibido para os estudantes. $\mathrm{O}$ assunto original da oficina, porém, foi alterado a pedido da escola, algumas semanas antes da data anteriormente acordada, conforme já expomos anteriormente.

\section{A oficina em ação, surpresas e desafios}

A elaboração da oficina consistiu em uma pequena apresentação utilizando slides, apresentação de vídeo da série "Ó pai ó”, aula expositiva sobre a escravidão e distribuição de imagens para os alunos pesquisarem sobre a celebridade brasileira que estava na foto. A utilização dessa metodologia se mostrou positiva. O local da aula foi 
na sala de informática, e não na sala de aula onde os estudantes realizavam suas atividades. Foi lá também que foi executada a primeira oficina.

A aula foi iniciada com uma questão problema, partindo de um vídeo da minissérie "Ó pai ó", produzida pela Rede Globo, em 2008. A cena tratava de um diálogo entre os personagens interpretados pelos atores Lázaro Ramos e Wagner Moura, sobre a questão racial que seria o tema da oficina. Nosso objetivo com o vídeo era iniciar um debate com os estudantes sobre o tema das questões raciais. Assim, partindo dos conhecimentos prévios dos alunos, o debate foi conduzido por meio de questões levantadas pelo grupo: Que lhes pareceu o filme? Que sensação lhes provocou? Que sentiram ao assisti-lo? Do que mais gostaram? E do que menos gostaram? O que mais lhe chamou a atenção? Que recursos, imagens ou sons os impactaram mais? Que reações lhes provocaram os personagens, as situações, fenômenos mostrados no filme? Vocês conhecem o filme?

Após o debate realizado em sala, ainda contando com breves falas e um pouco de timidez e insegurança por parte dos alunos para se expor, o grupo abordou a questão histórica da escravidão no Brasil. A oficina para este tema partiu da documentação acerca da Lei Áurea de 13 de maio de 1888. Escolhemos esse documento para abordar e discutir a questão da população afro-brasileira a partir da história da escravidão, e de como a mídia trabalha e trabalhou com esse ponto. O grupo aprofundou o conteúdo sobre a chegada dos escravos ao Brasil, desde o início da produção açucareira durante o século XVI. E após o período da escravidão, trouxemos novas informações para problematizar, buscando refletir sobre como foi e como é a vida da população afrobrasileira. Ainda com relação à escravização da população africana no Brasil, trabalhamos a questão das senzalas e os quilombos como forma de resistência dos afrodescendentes.

Durante a oficina exploramos ainda sobre como a imagem do afrodescendente foi construída no decorrer da História do Brasil. O objetivo do grupo de estágio era abordar como o imaginário do preconceito, em relação aos afro-brasileiros permaneceu, mesmo com o fim da escravidão. As oportunidades dentro da sociedade eram pequenas para os ex-escravos de então, sendo que a situação permanece, com outras formas, na sociedade de hoje em relação aos seus descendentes. Essa imagem de falta de oportunidades foi o que nós problematizamos junto aos estudantes. 
Várias foram as reações da turma, algumas inclusive que nos espantaram. Os alunos afro-descendentes da turma possuíam em suas faces feições como que de surpresa ou de que já sabiam, ainda que de forma superficial, tal como expuseram, como se deu a escravidão no Brasil, e como isso repercute até os dias de hoje, ainda com as problemáticas raciais. Já alguns colegas "brancos" não se contiveram e se expressaram preconceituosamente diante dos demais colegas, inclusive, fazendo piadas e chacotas da situação, dizendo que hoje não há mais discriminação e que todos são vistos igualmente. Esse foi um momento de grande tensão, nós não imaginávamos que iríamos nos deparar com tais situações em pleno século XXI. Todavia, tal movimentação demonstrou o quão era importante, e atual ainda, tratar desse tema com a turma.

Ao decidirmos abordar a Lei Áurea e o fim da escravidão, tomamos o cuidado de lembrar que o fim da escravidão no Brasil foi um processo lento e que não trouxe mudanças rápidas ao modo de vida dos afro-brasileiros. Sobre essa questão a autora Sylvia da Silveira Nunes (2006, p. 91) comenta:

\footnotetext{
A esperada cidadania após a abolição não aconteceu e, até hoje, é uma luta constante em uma sociedade em que a desigualdade racial é arraigada e as tentativas de apagar a memória da barbárie contra os escravos são permanentes, quer pela eliminação de documentos, quer pela disseminação do mito da democracia racial.
}

Abordar, inicialmente, a história da vinda dos africanos escravizados para o Brasil foi uma opção do grupo de estagiários e de primordial valor para dar uma contextualização temporal aos fatos. O propósito foi esclarecer historicamente como a ideia de exclusão dessa parte da população é secular na sociedade brasileira, desde a época do Brasil colonial até os dias de hoje. A abolição da escravatura não deixa de ser também uma das causas do racismo, que surge desde o momento em que o afrobrasileiro encontra-se vinculado aos seus antepassados, africanos escravizados, em uma perspectiva depreciativa. Importante dispor da reflexão quanto à palavra escravo, pois esta sempre foi uma imposição atribuída às pessoas em determinadas condições de trabalho. Equivoca-se aquele que associa tal expressão para generalizar a condição do negro, pois ninguém é "escravo". As pessoas foram e são "escravizadas".

Após a abolição, inúmeras lutas sociais para integrar os afro-brasileiros à sociedade esbarraram na visão instituída durante o período colonial, dificultando o 
acesso dessa parte da população às necessárias condições sociais de igualdade. A sociedade industrial, de mão-de-obra livre, não incorporou a população negra em função dos estereótipos, das discriminações e do racismo provenientes do termo "escravo". A hierarquia entre brancos e negros se manteve na "nova" ordem social dada pela princesa Isabel em 1888, pré-determinando que brancos possuíssem emprego e negros permanecessem às margens da sociedade brasileira.

De acordo com o artigo 35 da Resolução Imperial $n^{\circ} 382$, de $1^{\circ}$ de julho de 1854 , da província de Santa Catarina, era vetado aos escravos o acesso à escola, ou seja, a população afro-brasileira permaneceu marginalizada desde e por muito tempo:

\begin{abstract}
A educação permaneceu na esfera do desejo, pois as desvantagens ocupacionais, habitacionais e locacionais às quais a população negra estava submetida foram determinantes para a sua manutenção nos estratos educacionais mais baixos. Questionável saber se isso é consequência da pobreza ou da discriminação racial (BRASIL, 2003).
\end{abstract}

De acordo com essa compreensão sobre a discriminação, relacionada com a formação da sociedade brasileira, o racismo deu-se da seguinte forma:

A discriminação racial, na forma da racialização da experiência do negro, antecedeu à formação de uma sociedade de classes no Brasil, portanto a situação da população afrodescendente se explica na interseção entre a pertença étnico-racial e a estruturação de uma sociedade de classes (BRASIL, 2003).

Diante desses fatos, o grupo considerou necessário trazer e expor mais a respeito do documento conhecido como Lei Áurea, problematizando seus impactos na sociedade brasileira como forma de trabalhar mais a fundo as prerrogativas da discriminação em relação ao racismo. Algumas questões foram levantadas: a carta que a princesa Isabel assinou, em 1888, libertando os escravos, continha que interesses por trás? Onde os escravos foram morar, como viviam e como conseguiam arcar com as despesas para sobreviver? Estas questões nos auxiliaram a conduzir a temática da aula até iniciarmos a abordagem do racismo. A proposta era problematizar com os alunos por que e como esse tipo de preconceito ainda persiste em nossa cultura e como muitos ainda o nega.

$\mathrm{Na}$ primeira parte da oficina, o grupo de estágio realizou uma exposição do conteúdo, com apresentação de um vídeo, imagens de artistas que sofreram racismo na mídia e uma aula expositiva a respeito da escravidão. No final desta primeira parte da 
oficina houve um debate entre os alunos, no qual vários demonstraram ainda terem opiniões de cunho racista. Foram ditas frases pelos estudantes, tais como: "o sol nasce para todos", "as oportunidades estão disponíveis para toda a sociedade e só não as consegue quem não as quer”. Outros alunos relataram suas dificuldades por serem afrobrasileiros e que já tinham sofrido racismo no trabalho pela cor de sua pele. Houve um momento em que todos os alunos quiserem dar sua opinião a respeito do assunto, e nesse momento tivemos que intervir para "acalmar" o debate. A professora Rosiane Ribeiro Bechler, nossa orientadora de estágio da UFSC, fez uma complementação ao debate que estava acontecendo, relatando que o racismo persiste de variadas formas em nossa sociedade, que ainda é cheia de preconceitos.

Esse ocorrido foi assustador para o grupo por dois motivos. Realmente não sabíamos a dimensão, nem o quão a sociedade brasileira ainda é racista, estando nós incluídos nela. Percebemos, pois, como em nossa rotina diária estamos submersos numa cultura que exclui pessoas pela cor e não se percebe como tal, excludente! Mesmo nós estagiários não sendo, nenhum de nós, afrodescendentes, sentimos o sofrimento e o desespero que nossos alunos afrodescendentes estavam passando naquele momento, e pelo qual passam todos os dias. Essa experiência expôs para nós que os reflexos do racismo é uma atitude a ser enfrentada cotidianamente pelos sujeitos afros, mas especialmente por aqueles que também exercem a docência e tratam do assunto em sala de aula.

Quando os ânimos foram acalmados, o grupo de estagiários tentou (re)esclarecer a respeito da diferença entre racismo e preconceito e como o preconceito, em relação à população negra, foi algo historicamente construído e herdado do longo período de escravidão no Brasil. Mas observamos que alguns alunos estavam irredutíveis no seu ponto de vista a respeito deste assunto.

No segundo momento da oficina entregamos imagens para que os alunos pesquisassem a respeito do artista/celebridade ali apresentado, e descrevessem se este já havia sofrido algum tipo de preconceito racial e seu posicionamento com relação a isso. Houve repetição de imagens oferecidas aos alunos e o interessante é que cada um escreveu o que chamou sua atenção, o que, muitas vezes, não foi o mesmo fator que chamou a atenção do colega. De fato, cada sujeito carrega consigo uma representação distinta, sendo estas construídas com base nas relações sociais que estabelecem e na 
experiência pessoal de cada sujeito. Houve relatos de alunos a respeito de vários assuntos. Um exemplo foi sobre o futebol. Uma das estudantes trouxe seu relato de como, no início, o futebol era um esporte da elite, e que para os negros atuarem como jogadores eles se maquiavam com pó de arroz, clareando o tom de pele. A partir disso debatemos que, ainda hoje, há times de futebol, e suas respectivas torcidas, que se identificam mais com a população "branca" e outros com a população negra. É factível também lembrar, mas que no momento não o foi, que o time do Vasco da Gama, da capital do Rio de Janeiro, foi o primeiro time brasileiro a aceitar negros como jogadores.

Ao final da oficina a professora da turma pediu a palavra e reforçou que tudo que foi dito, mostrado e discutido seria muito interessante para a Conclusão do Curso dos alunos, que iriam elaborar slides a respeito dos afro-brasileiros.

Nosso grupo de estagiários ficou satisfeito ao finalizar a oficina e, ao mesmo tempo, chocado, pois, quando falávamos de racismo não pensávamos que ele estivesse tão presente e de maneira tão agressiva. A grande desigualdade de acesso aos bens materiais e culturais que os afro-brasileiros ainda sofrem é algo que precisa ser reconhecido e principalmente debatido. E esses debates podem começar dentro de uma sala de aula, não importando a sua configuração ou etapa de escolarização.

\section{Considerações finais}

A experiência do estágio possibilitou muitos aprendizados e aperfeiçoamento, no trato à docência, dos integrantes do grupo de estágio. $\mathrm{O}$ momento oportuno de fazer o estágio dentro de uma sala de aula da EJA transpôs muitas barreiras pessoais e nos acrescentou o conhecimento prático como educadores que ministraram uma oficina.

Percebeu-se que é papel do professor, inserido em nossa formação pelo currículo da graduação em História, atuar na EJA de maneira a compreender melhor o aluno e sua realidade diária, acreditando nas possibilidades do indivíduo, ajudando-o na busca do seu crescimento pessoal e profissional.

No contexto do Curso de Informática, tivemos o intuito de permitir ao aluno historicizar a evolução tecnológica e os usos do computador e de demais artífices a ele ligados, além de abordar também a importância dessa ferramenta no meio de trabalho no qual eles se inserem. É de suma importância, a nosso ver, motivar e gerar debates 
críticos acerca desse contexto, pois assim como há o debate significativo na questão do acesso ao mercado de trabalho, ainda que, num contexto de inclusão que a informática gera, ela mesma também pode ser responsável por excluir os sujeitos.

O fato de todos nós sermos seres inacabados exige que tenhamos respeito com a autonomia e saberes dos outros (FREIRE, 1996). Esse respeito às leituras de mundo e à autonomia que Paulo Freire defende com tanta veemência pode ser notado na sala de informática da Escola. Os estudantes são de idades variadas e de lugares e contextos diversos e todos têm motivos e incentivos diferentes para estar no Curso, ou seja, a diversidade pode estar presente em todos os cursos da EJA.

O grupo concorda com Paulo Freire (1996) quando ele relata acerca da criação de uma proposta curricular coerente. O educador precisa de fato partir do seu conhecimento de vida e do conhecimento de vida do educando para criar um currículo apropriado à necessidade encontrada, se assim não fizer, o educador estaria fadado ao fracasso. Ou seja, é importante que cada aluno contribua com suas lembranças e experiências para a elaboração do currículo/aula, haja vista ser fundamental que todos se sintam inseridos neste processo.

Priorizar o que é relevante para a turma é essencial, ao mesmo tempo em que se repensa as formas de mediação dos conteúdos e de avaliação na EJA. Valorizando a sabedoria dos alunos e estabelecendo analogias e ligações com a realidade deles, gera-se um diálogo no processo de aprendizagem, ao mesmo tempo em que os estudantes vão se sentir menos tímidos, rompendo assim o desconforto de estarem aprendendo tardiamente, e sentindo-se confiantes para se exporem e exporem o que pensam.

Em se tratando da oficina, ela se desenvolveu de maneira bem polêmica. A proposta era que houvesse bastante debate, onde cada aluno pudesse colocar o que pensava a respeito do assunto. Foram levados para a sala de aula vídeos, imagens de artistas famosos que sofreram racismo e reportagens a respeito do assunto. Pensamentos e discussões não faltaram. Apesar de perceber, pessoalmente, que a sociedade, ali representada pelos alunos, ainda pode ser considerada racista, o grupo de estágio acredita que o fato de um assunto como esse poder ser debatido hoje, já representa um passo importante. Há ainda muitos avanços a serem feitos. Por parte dos nossos alunos, embora ainda possam manter ideias racistas, estes tiveram a oportunidade de refletir 
sobre os aspectos concernentes à temática, por meio da experiência de estágio propiciada por aquilo que planejamos e desenvolvemos da melhor maneira possível.

Com relação à história dos africanos escravizados no Brasil há muitos pontos de vista que foram debatidos, analisados e explorados. É por esse pensamento que nós, estagiários, por meio da prática do estágio obrigatório da UFSC, aspiramos desenvolver e praticar essa forma de ensinar, não nova, mas mais humana de lidar com jovens e adultos na educação e no ensino de História, pois entendemos que o papel do professor, em sala de aula, não é o de tão somente repassar conhecimento. Nem ser inflexível ou mesmo dono do saber. Essa não é a função e nem o papel do professor ou dos estagiários. Faz parte da nossa responsabilidade as escolhas que faremos para abordar um assunto, ou a forma como conduziremos as aulas, ou mesmo motivar e garantir que a aula seja produtiva. Ser professor não é concluir um dia de aula, mas concluir uma etapa na educação do seu aluno.

\section{Referências}

ARROYO, Miguel. A Educação de Jovens e Adultos em tempos de exclusão. Alfabetização e Cidadania, Revista de educação de jovens e adultos, São Paulo, n. 11, p. 9-20, 2001.

BRASIL. Lei 10.639/2003 e o ensino de História e Cultura Afro-Brasileira e Africana. Disponível em: http://educador.brasilescola.uol.com.br/estrategias-ensino/lei-10639-03ensino-historia-cultura-afro-brasileira-africana.html. Acesso em: 26 abr. 2016

FREIRE, Paulo. Pedagogia da autonomia: Saberes necessários à prática pedagógica. São Paulo: Paz e Terra, 1996.

Pedagogia do oprimido. Rio de Janeiro: Paz e Terra, 1983.

NICODEMOS, Alessandra. Ensino de História na EJA: o legado da educação popular e os desafios docentes na formação do aluno jovem e adulto trabalhador. ANAIS do XXVII Simpósio Nacional de História, Natal (RN), p. 1-15, 2013.

Práticas Docentes na Educação de Jovens e Adultos: Conscientização ou Conversão? Periferia: educação, cultura e comunicação, Rio de Janeiro, FEBF/UERJ, v.6, n. 1, p. 88-102, jan./jun./2014.

NUNES, Sylvia da Silveira. Racismo no Brasil: tentativas de disfarce de uma violência explícita. Psicologia USP, São Paulo, v.17, n. 1, p. 89-98, 2006. 
62 Polyphonía, v. 29/1, jan./jun. 2018

TARDIF, Maurice; LESSARD, Claude; LAHAYE, Louise. Os professores face ao saber: esboço de uma problemática do saber docente. Teoria \& Educação, Porto Alegre, Pannônica, n. 4, p. 215-223, 1991.

Recebido em: 27 abr. 2018.

Aceito em: 28 maio 2018. 